Section Editors

David C. Spencer, MD

Steven Karceski, MD

\title{
Teens, migraine, suicide, and suicidal thoughts
}

Andrew D. Hershey, $\mathrm{MD}, \mathrm{PhD}$, FAHS
Migraine can be a disabling pain condition that episodically and often unpredictably impacts patients. For teens, this can mean missed activities. Teens may withdraw from activities with friends and from school work. In adults with migraine, it is believed that there may be a connection between migraine and depression. It is unclear whether these two conditions simply occur together, or whether one causes the other.

Suicidal ideation, or thinking about suicide, is more common during the teen years. These issues in the teen years are difficult because teens are still developing. The presence of an ongoing health condition, especially if it is under-recognized, like migraine, may add further complications. There always needs to be an awareness of these issues when caring for teens with migraine.

WHAT WAS THIS STUDY ABOUT? In this issue of Neurology ${ }^{\circledR}$, a study by Dr. Wang and coauthors (Migraine and suicidal ideation in adolescents aged 13 to 15 years. Neurology 2009;72:1146-1152) examined the connections between migraine and suicidal ideation in teens aged 13 to 15 years. The goal of this study was to compare how often teens with migraine had suicidal ideation compared to teens in general. The authors wanted to see whether teens with migraine had more suicidal ideation and whether there were factors that could predict who of those teen sufferers would be at greatest risk.

HOW WAS THE STUDY DONE? The authors surveyed nearly 4,000 teens in middle school (seventh to ninth grade) in Taiwan. This is a large sample of the over 9,000 middle school children of this age in the area. They included teens in urban and rural schools. The survey was designed to describe headaches, migraine, chronic daily headaches, and psychological or emotional issues in the teens. The teens completed the surveys in class with the help of teachers and school nurses. The survey had 4 parts: a demographic section, a headache questionnaire based on current standards, a depression assessment, and a disability assessment.

From the results of the survey, the authors were able to look at four items:
1. The demographic features of teens with headache

2. The headache diagnosis using current standards

3. The presence of depression and related psychological factors

4. The disability of teens with migraine vs the total population

\section{WHAT WERE THE MAIN FINDINGS?}

How common was migraine? The authors found that headache was common in this group of teens. Eighty-six percent reported having a headache in their lifetime. About $62 \%$ had a headache within the 3 months of completing the survey. Nearly a quarter of the teens reported having migraine. "Probable migraine" was the most common $(11.2 \%$ of the total population studied). After that, $8.7 \%$ teens had migraine without aura (for definition of aura, see below) and $3.5 \%$ had migraine with aura.

Depression. Using the Adolescent Depression Inventory, a test to measure depression, a higher score was seen in girls. Teens with migraine scored higher than teens without migraine. There was a trend toward more depression in teens who had migraine with aura.

Suicidal ideation. Of all the teens surveyed, 337 (8.5\%) reported thinking about suicide in the month prior to the survey. This was higher in girls than boys and higher in teens with depression. It was lowest in teens who lived with both biological parents. For teens with any type of headache, both increased headache frequency and increased disability were associated with increased suicidal thoughts. When headaches happened 7 to 14 times per month, 18\% had suicidal ideation. For those who had more than 15 headaches per month, the rate of suicidal ideation was $28.6 \%$. Teens with low disability due to their headaches had a rate of suicidal thoughts $(7.5 \%)$ that was similar to that in the general population (8.5\%). However, teens with high disability experienced a high rate $(44.4 \%)$ of suicidal thoughts.

When the authors examined the diagnosis of the headaches in these teens, they found that suicidal thoughts were more common in teens who had migraine with aura $(23.9 \%)$ compared to 
teens who had migraine without aura $(15.9 \%)$ or probable migraine (13.7\%). Although migraine with aura was less common than the other headache conditions, they did find that these teens were 4.6 times more likely to have suicidal thoughts than those teens without migraine.

When the authors tried to identify the main factors that were important for suicidal ideation, they found that migraine with aura and high frequency of headaches (more than 7 days per month) were the most important independent factors.

WHY IS THE STUDY IMPORTANT? This study emphasizes the importance of addressing psychological factors in teens with headache. Frequency of headaches and disability increase the risk of suicidal thoughts. In addition, the specific headache type "migraine with aura" also contributes to these thoughts.
WHAT IS THE BOTTOM LINE? Teens with frequent headaches need to be asked about suicidal thoughts. Health care providers and families need to have a plan in place to deal with these thoughts and their consequences. Determining the type of headache using standardized criteria may help assess the risk.

WHAT FUTURE RESEARCH IS NEEDED? This study examines the baseline suicidal thoughts in a population of teens. It would be interesting and useful to understand the psychology and biology of headaches that are responsible for these findings. It also needs to be investigated whether effective treatment reverses these suicidal thoughts. It is not known whether the increased suicidal thoughts extend to suicide attempts or suicide itself. If either of these does increase, it raises the urgency of recognizing and treating recurrent headache and migraine. 
WHAT IS MIGRAINE? Migraine is a recurrent headache disorder with specific features and associated symptoms. It is often underrecognized due to a misunderstanding of these features.

WHAT ARE THE SYMPTOMS OF MIGRAINE? The International Classification of Headache Disorders, 2nd Edition, outlines the rules for diagnosing all headache types. ${ }^{1}$ For migraine these criteria require the following:

1. Recurrent headaches (at least five) that last untreated between 4 and 72 hours

2. At least two of the following features:

a. Location in a specific part of the head

b. Moderate to severe pain

c. A throbbing quality

d. Worsening or stopping activity

In addition to these features ( $\mathrm{a}-\mathrm{d}$ above), the headaches must also have nausea and/or vomiting, or light and sound sensitivity.

Finally, the neurologic examination should be normal and there should be no secondary causes of headache clearly evident.

WHAT ARE THE SYMPTOMS OF MIGRAINE WITH AURA? In addition to the symptoms of migraine without aura - a neurologic warning that they are going to have a migraine - patients who have migraine with aura need to have at least two headaches with an aura. These auras are typically either visual, sensory, or cause difficulty talking. The auras should go away completely and last between 5 minutes and 1 hour. The headache should start within 1 hour of the start of the aura.

WHAT ARE THE DIFFERENCES IN CHILDREN AND TEENS? These criteria are modified for the diagnosis in children and teens. Children tend to have shorter headaches that are more likely to be on both sides of the head. Young children may have problems describing their headache symptoms. To account for these issues, the criteria allow for some differences. Children are allowed to have a duration of 1 to 72 hours and a location on both sides of the head. Some of the symptoms may be reported by the parents. Migraine, however, remains a disease of patient report. This explains why "probable migraine" was the most frequent diagnosis noted in the current study.

WHY DOES MIGRAINE HAVE PSYCHOLOGICAL COMPONENTS? Migraine can affect a child's and family's lives. As more migraines occur, there is an increase in these psychosocial stressors to the teen. This involves lost school days and a decrease in time spent with friends. Teens with migraine also might fear being different from their friends. ${ }^{2,3}$ For parents, their child's migraine can lead to lost days of work, anxiety of seeing their children in pain, and sometimes doubt about their child's condition.

In addition, migraine is seen as a neurologic condition. During attacks there may be clear neurologic changes, especially if aura is present. There is also research that has shown that there are mild neurologic problems between attacks. ${ }^{4}$ It is likely that psychosocial and neurologic factors together result in unique psychological risks.

WHAT NEEDS TO BE DONE TO HELP MINIMIZE THIS PROBLEM? Physicians and parents need to recognize and manage headache well to limit its psychological impact. Recognition requires understanding that headache is a problem and that migraine, if not properly cared for, may get worse. It is also important to diagnose any other conditions that are often seen with headaches, including psychiatric conditions and psychological stresses.

Successful treatment can stop an individual attack and prevent more attacks. Also, treatment should include helping teens learn how to cope with migraine. Because suicidal ideation is increased, it is also clear that this should be addressed with a specific plan.

\section{FOR MORE INFORMATION}

American Headache Society

www.americanheadachesociety.org

AHS Committee for Headache Education (ACHE)

www.achenet.org

International Headache Society

www.i-h-s.org 


\section{REFERENCES}

1. Headache Classification Subcommittee of the International Headache Society. The International Classification of Headache Disorders. Cephalalgia 2004;24(suppl 1):1-160.

2. Hershey AD, Powers SW, Vockell AL, LeCates SL, Segers A, Kabbouche MA. Development of a patient-based grading scale for PedMIDAS. Cephalalgia 2004;24:844-849.
3. Vannatta K, Getzoff EA, Gilman DK, Noll RB, Gerhardt CA, Powers SW, et al. Friendships and social interactions of school-aged children with migraine. Cephalalgia 2008; 28:734-743.

4. Jakubowski M, Silberstein S, Ashkenazi A, Burstein R. Can allodynic migraine patients be identified interictally using a questionnaire? Neurology 2005;65:1419-1422. 


\title{
Neurology
}

\author{
Teens, migraine, suicide, and suicidal thoughts \\ Andrew D. Hershey \\ Neurology 2009;72;e61-e62 \\ DOI 10.1212/01.wnl.0000346519.27392.ad
}

\section{This information is current as of March 30, 2009}

\section{Updated Information \&}

Services

Supplementary Material

References

Permissions \& Licensing

Reprints including high resolution figures, can be found at: http://n.neurology.org/content/72/13/e61.full

Supplementary material can be found at: http://n.neurology.org/content/suppl/2009/03/28/72.13.e61.DC1

This article cites 4 articles, 1 of which you can access for free at: http://n.neurology.org/content/72/13/e61.full\#ref-list-1

Information about reproducing this article in parts (figures,tables) or in its entirety can be found online at:

http://www.neurology.org/about/about_the_journal\#permissions

Information about ordering reprints can be found online:

http://n.neurology.org/subscribers/advertise

Neurology ${ }^{\circledR}$ is the official journal of the American Academy of Neurology. Published continuously since 1951, it is now a weekly with 48 issues per year. Copyright. All rights reserved. Print ISSN: 0028-3878. Online ISSN: 1526-632X.

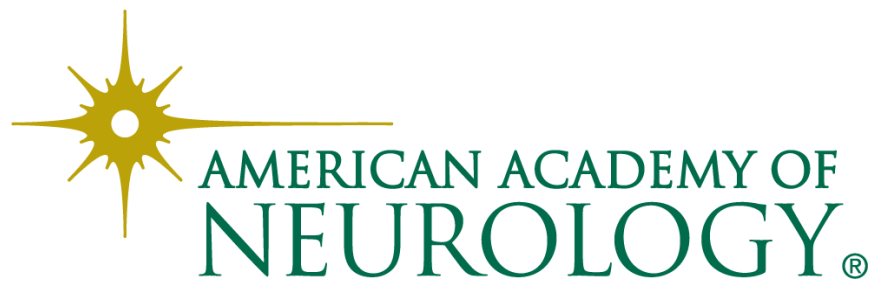

